\title{
On the Accuracy Assessment of the Latest Releases of GOCE Satellite-Based Geopotential Models with EGM2008 and Terrestrial GPS/Levelling and Gravity Data over Egypt
}

\author{
Mohamed El-Ashquer'1, Basem Elsaka²,3, Gamal El-Fiky \\ ${ }^{1}$ Construction Engineering and Utilities Department, Faculty of Engineering, Zagazig University, Zagazig, Egypt \\ ${ }^{2}$ National Research Institute of Astronomy and Geophysics (NRIAG), Helwan, Cairo, Egypt \\ ${ }^{3}$ Institute of Geodesy and Geoinformation, University of Bonn, Bonn, Germany \\ Email:elsaka@geod.uni-bonn.de
}

How to cite this paper: El-Ashquer, M., Elsaka, B. and El-Fiky, G. (2016) On the Accuracy Assessment of the Latest Releases of GOCE Satellite-Based Geopotential Models with EGM2008 and Terrestrial GPS/Levelling and Gravity Data over Egypt. International Journal of Geosciences, 7, 1323-1344. http://dx.doi.org/10.4236/ijg.2016.711097

Received: October 6, 2016

Accepted: November 26, 2016

Published: November 29, 2016

Copyright $\odot 2016$ by authors and Scientific Research Publishing Inc. This work is licensed under the Creative Commons Attribution International License (CC BY 4.0).

http://creativecommons.org/licenses/by/4.0/

(c) (i) Open Access

\section{Abstract}

The Global Geopotential Models (GGMs) of GOCE (Gravity Recovery and steadystate Ocean Circulation Explorer) differ globally as well as regionally in their accuracy and resolution based on the maximum degree and order (d/o) of the fully normalized spherical harmonic $(S H)$ coefficients, which express each GGM. The main idea of this study is to compare the free-air gravity anomalies and quasi geoid heights determined from several recent GOCE-based GGMs with the corresponding ones from the Earth Gravitational Model 2008 (EGM2008) over Egypt on the one hand and with ground-based measurements on the other hand. The results regarding to the comparison of GOCE-based GGMs with terrestrial gravity and GPS/levelling data provide better improvement with respect to EGM2008. The 4th release GOCE-based GGM developed with the use of space-wise solution strategy (SPW_R4) approximates the gravity field well over the Egyptian region. The SPW_R4 model is accordingly suggested as a reference model for recovering the long wavelength (up to $\mathrm{SH}$ d/o 200) components of quasi geoid heights when modelling the gravimetric quasi-geoid over the Egypt. Finally, three types of transformation models: Four-, Fiveand Seven-parameter transformations have been applied to reduce the data biases and to provide a better fitting of quasi geoid heights obtained from the studied GOCE-based GGMs to those from GPS/levelling data. These models reveal that the standard deviation of vertical datum over Egypt is at the level of about $32 \mathrm{~cm}$.

\section{Keywords}

GOCE-Based GGMs, Free-Air Gravity Anomalies, GPS/Levelling Data, Spectral 
Enhancement Method (SEM)

\section{Introduction}

The Gravity field and steady-state Ocean Circulation Explorer (GOCE) gravity satellite mission was a part of ESA's (European Space Agency) Living Planet program [1] launched in the period between March 2009 and October 2013. Since begin of 2010, consecutive highly accurate GOCE-based (GOCE-only and combined) static Global Geopotential Models (GGMs) were developed using GOCE observations. The latest releases of GOCE-based GGMs have been made available to the user community in the mid of 2014, which incorporate the complete mission data set exhibiting a significant higher spatial resolution [2]. Up to now, GOCE-based GGMs represent the best estimate of the gravity field anomalies and mean quasi geoid heights observed from the space with a precision of about $1 \mathrm{mGal}$ and $1-2 \mathrm{~cm}$, respectively.

Three types of GOCE-based GGMs are developed through the European Space Agency (ESA) project GOCE High-level Processing Facility (HPF) [3] [4], processed mainly by three approaches: direct (DIR) [5], time-wise (TIM) [6] and space-wise (SPW) [7]. For more description, the readers are referred to [4]. The maximum achieved spatial resolution of GOCE-based GGMs of types SPW, TIM and DIR ranges from $83.5 \mathrm{~km}, 71.5 \mathrm{~km}$ and $66.8 \mathrm{~km}$, respectively based on the formula:

$$
N_{\max } \approx \frac{2 \pi R_{E}}{\lambda} \approx \frac{\pi R_{E}}{D}
$$

where $N_{\max }$ is the maximum spherical harmonics $(S H)$ degree; $R_{E}$ is the mean radius of the Earth at the reference ellipsoid $(\approx 6378.137 \mathrm{~km}) ; D$ is the spatial resolution (i.e. half of wavelength $\lambda$ ) in $\mathrm{km}$.

Moreover, other solutions of GOCE-based GGMs have been developed by different research groups such as the Gravity Observation Combination (GOCO) models [8], the European Improved Gravity models of the Earth by New techniques (EIGEN) model series [9] [10] [11], the Delft Gravity Model (DGM) solution [12] and the Bonn (Institute of Geodesy and Geoinformation, University of Bonn) solution (ITG-GOCE02) [13].

To ensure the best accuracy of GOCE-based GGMs, especially for the local/regional geoid modeling issue, evaluation with the use of ground-based gravity data is quite important. Thus, our goal here is to examine which of GOCE-based GGMs approximate closely the gravity field over Egypt and in which spectral bands they do deliver improved information. We have to mention here that several studies concerning the validation as well as the accuracy assessment of GOCE-based GGMs have been performed in different regions of the world by different research teams, e.g. [14] [15] [16] worldwide; [17] [18] in Germany; [19] in Central Europe: [20] in Poland; [21] in Norway; [22] in Brazil; [23] [24] in Sudan and [25] in Saudi Arabia.

In the following, the gravity field functionals in terms of quasi geoid heights and 
free-air anomalies as determined from different of GOCE-based GGMs compared with the corresponding ones from the Earth Global Model 2008 (EGM2008, [26]) at both global and regional scales over Egypt are examined. In addition, a comparison between the ground-based (terrestrial) free-air anomalies and the corresponding one obtained from GOCE-based anomalies is performed. For consistent validation in the later comparison, maximum d/o of GOCE-based GGMs will be completed using EGM2008 up to d/o 2190. In addition, the gravity signals induced beyond 2190 are compensated from local topography information which is considered as a remaining omission error.

\section{Datasets}

The datasets used in this study consist of: 1) GOCE-based GGMs and EGM2008; 2) terrestrial free-air gravity anomalies and GPS/levelling data collected over the Egyptian region; and 3) High-resolution topographic data from the SRTM30_PLUS (Shuttle Radar Topography Mission) digital terrain model.

\subsection{GOCE-Based GGMs and EGM2008}

Over the past years, numerous GOCE-based GGMs have been developed differing in their observations time period and their processing strategies. The time span of GOCE observations range from release 1 to 5 of about $0.16,0.66,1.5,2.75,4$ years, respectively. In the current investigation, eight GOCE-based GGMs based on mainly the three approaches of direct (DIR), time-wise (TIM) and space-wise (SPW) are used. These models are available via the International Centre for Global Earth Models (ICGEMs) web-service icgem.gfz-potsdam.de/ICGEM/ in terms of geopotential spherical harmonic coefficients $(S H)$. The characteristics of those models are summarized in Table 1 .

Moreover, beside GOCE-based GGMs, EGM2008 Global Geopotential Model is used in this study as state-of-the-art high resolution GGM for evaluating GOCE-based GGMs as well as for estimating higher gravity signal, i.e. the gravity signal beyond the applied maximum resolution of GOCE-based GGMs. When developing EGM2008, over Africa, the values of $5^{\backslash} \times 5^{\backslash}$ mean gravity anomalies were synthesized using GGM02S spherical harmonic coefficients [27] for degrees 2 - 60; coefficients for degrees 61 - 360 were augmented with those of EGM96 [28], and for further degrees, i.e. 361 2159 coefficients were augmented from the analysis of the residual terrain modelling [26]. This model has been extensively evaluated worldwide. Its fit to the African geoid measured with standard deviation of geoid height differences was evaluated as equal to $0.73 \mathrm{~m} \mathrm{[29].}$

\subsection{Terrestrial Data}

\subsubsection{Free-Air Terrestrial Gravity Data}

The available point gravity anomalies dataset in this study consists of 930 stations. Figure 1 shows the distribution of the free-air gravity anomalies for Egypt used for the current study indicated from two different sources. The date of these observations and 
Table 1. The main characteristics of the investigated GOCE-based GGMs.

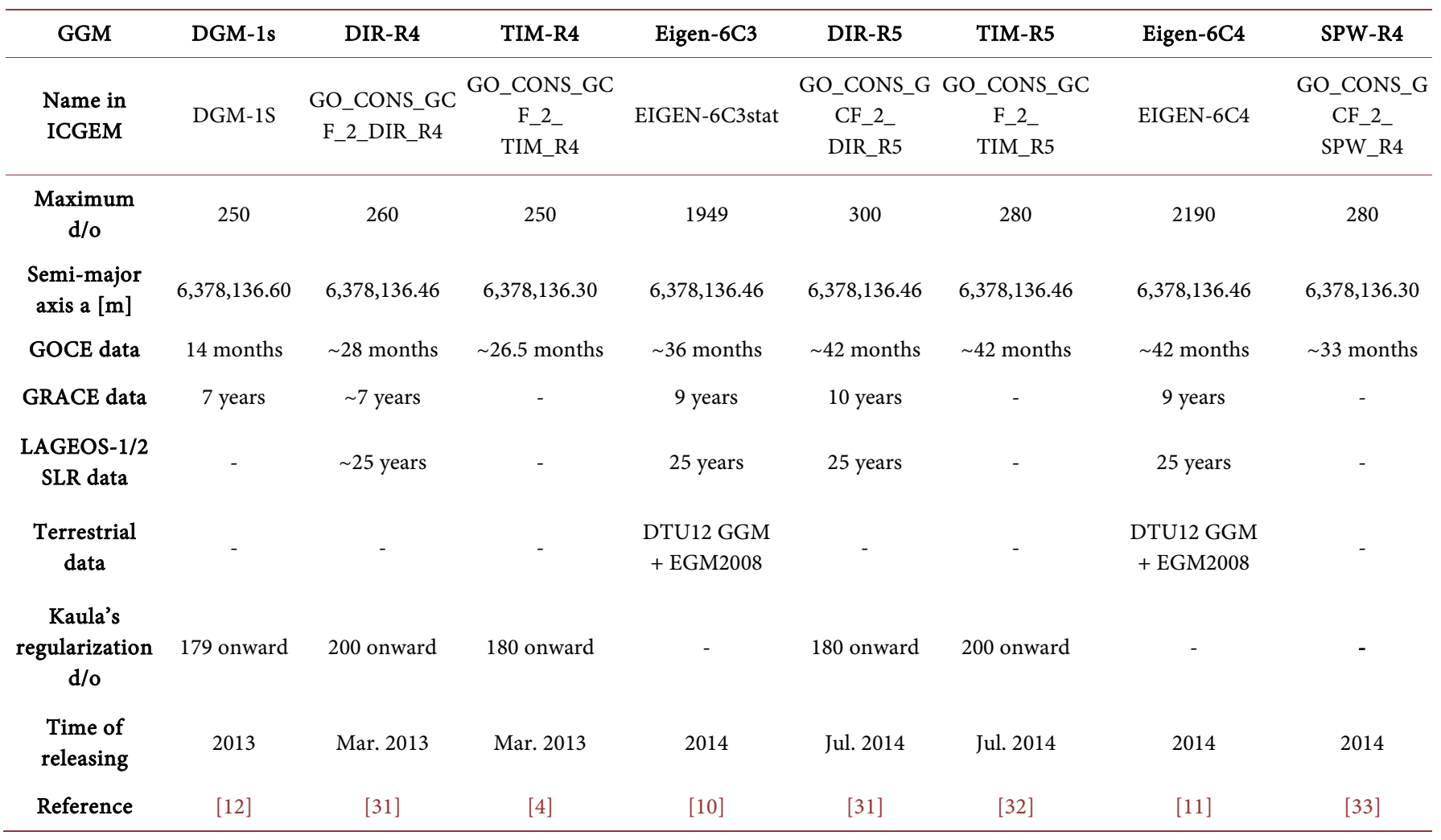

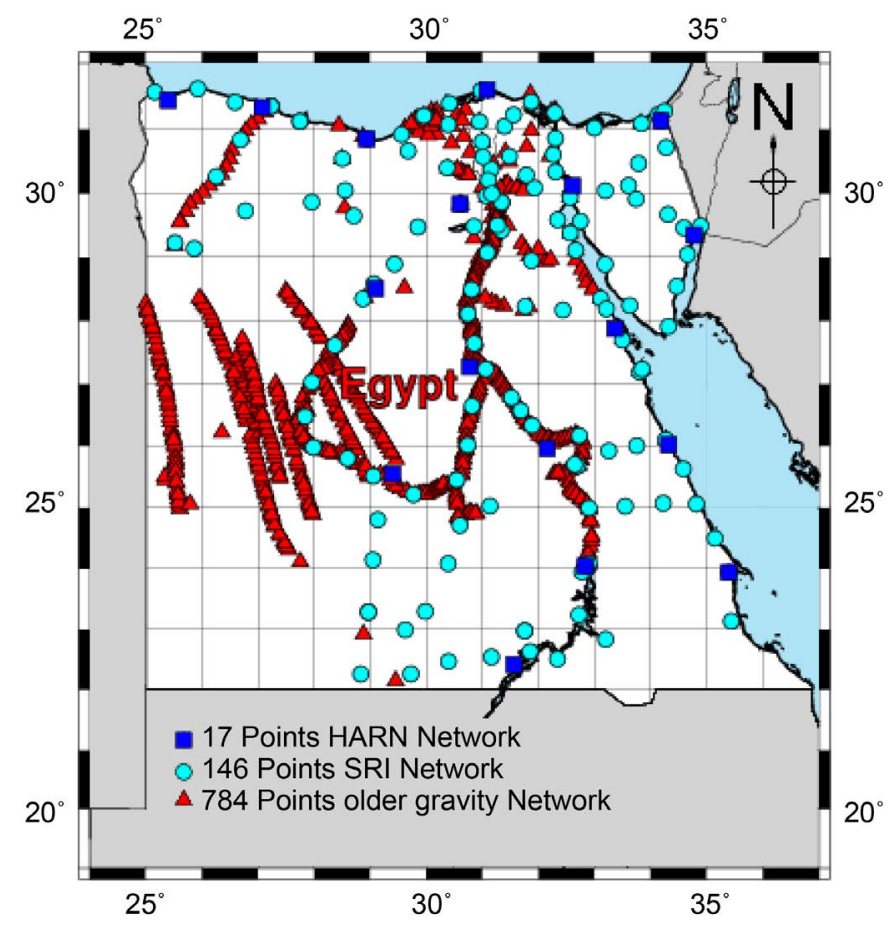

Figure 1. Distribution of the 784 and 146 gravity stations from older gravity network and SRI network, respectively and 17 GPS/levelling benchmarks in Egypt. 
their accuracy vary greatly between the most recent Egyptian National Gravity Standardization Network of 1997 (ENGSN97), which was established by the Survey Research Institute (SRI) (146 stations), and older gravity (784 stations) surveys carried out by many private organizations several decades ago. The accuracy of ENGSN97 gravity values is $0.022 \mathrm{mGal}$, while the accuracy estimate for older gravity data is $0.5 \mathrm{mGal}$ on average [30].

\subsubsection{GPS/Levelling Data}

GPS/levelling dataset available here consists of 17 stations of the Egyptian National High Accuracy Reference Network (HARN) observed by the Egyptian Survey Authority to form the New Egyptian Datum 1995 (NED-95), distributed over Egypt as shown in Figure 1. In this network, the GPS observations were tied to the International Geodetic Stations (IGS) reference system. It should be mentioned that, the HARN network consists of 30 stations, but 13 stations (located in remote areas) have no observed orthometric heights and consequently, no undulations could be obtained for these stations. The precision of the HARN network is 0.1 parts per million (ppm), which can be written in another form as 1:10,000,000. Although the HARN network consists of 30 stations, only 17 points among them have first order levels. The precision of geoid undulations at these stations has been suggested from the provider of about $1 \mathrm{~cm}$ or lower. Despite the fact that the distribution of the GPS/levelling dataset of 17 stations is rather sparse, one may use them for the assessment purpose since these stations cover almost the whole Egyptian territory in different areas [34].

\subsection{High-Resolution Terrain Data}

The SRTM30_PLUS (Shuttle Radar Topography Mission of spatial resolution about $\sim 900 \mathrm{~m}, 30$ arc-sec) data is used in this study to compute the topographic potential effect on the geoid over Egypt region. The SRTM30_PLUS has been provided by the institution of Oceanography, University of California. The detailed information concerning the development of the SRTM30_PLUS are given in the website http://topex.ucsd.edu/WWW_html/srtm30_plus.html. Figure 2 depicts the topography of Egypt from the SRTM30_PLUS.

\section{Difference Amplitude of EGM2008 vs. GOCE-Based GGMs}

Quasi geoid heights computed from GOCE-based GGMs and the corresponding ones obtained from EGM2008 on both global and regional scales are now compared. On the global scale, degree variances are often used to quantify the power of signal and error in the gravity field estimates at various spectral wavelengths to quantify the powers of signal and error in the gravity field estimates at various spatial wavelengths as ([35], pp. 98)

$$
\Delta \sigma_{n}=\sqrt{\sum_{m=0}^{n}\left(\Delta c_{n m}^{2}+\Delta s_{n m}^{2}\right)},
$$

with $\Delta c_{n m}$ and $\Delta s_{n m}$ are the differences between $S H$ coefficients of GOCE-based 


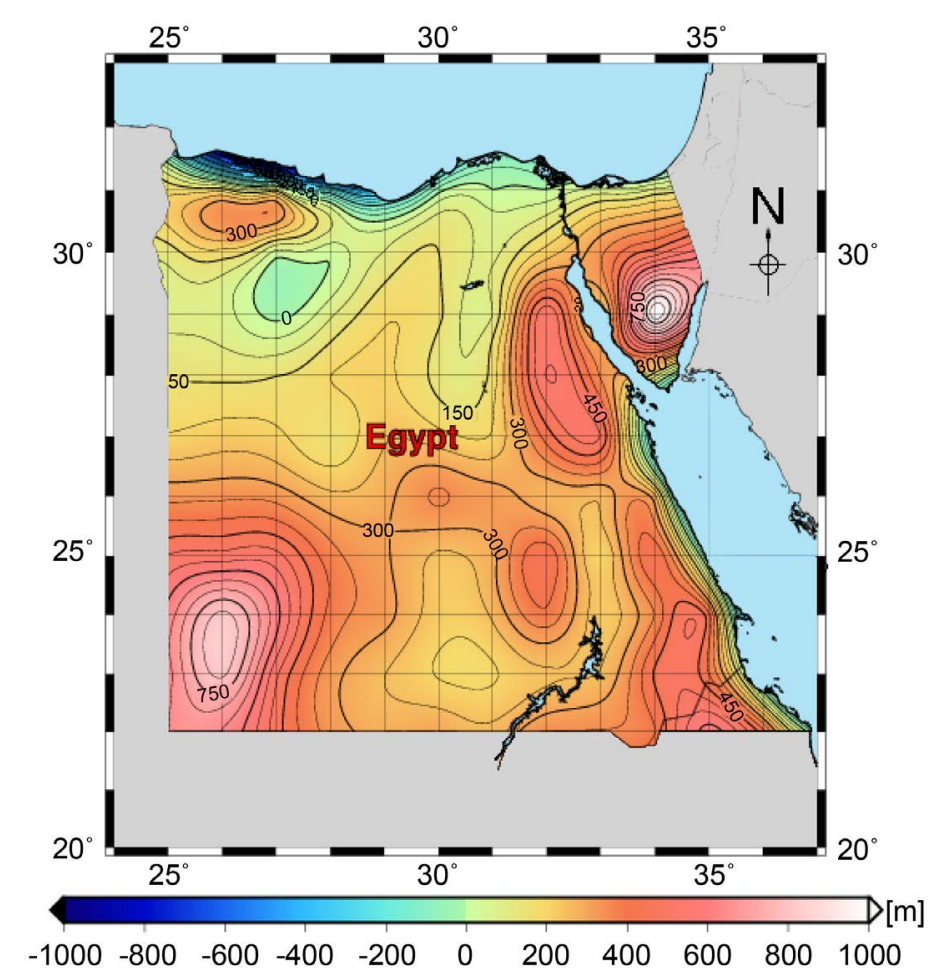

Figure 2. Topographic map showing heights in [m] as deduced from the SRTM30_PLUS data.

GGMs and the corresponding ones from the EGM2008 and $n, m$ are degree and order of spherical harmonics, respectively. They read as follows

$$
\begin{gathered}
\Delta c_{n m}=\left(c_{n m}\right)_{\mathrm{GOCE}}-\left(c_{n m}\right)_{\mathrm{EGM} 2008}, \\
\Delta s_{n m}=\left(s_{n m}\right)_{\mathrm{GOCE}}-\left(s_{n m}\right)_{\mathrm{EGM} 2008} .
\end{gathered}
$$

Accordingly, the difference degree variances of geoid heights as shown in Figure 3 were computed here as:

$$
\Delta \sigma=R_{E} \sqrt{\sum_{m=0}^{n}\left(\Delta c_{n m}^{2}+\Delta s_{n m}^{2}\right)} .
$$

With $R_{E}$ is the mean radius of the Earth at the reference ellipsoid $(\approx 6378.137 \mathrm{~km})$, the fully normalized spherical harmonics, $c_{n m}$ and $s_{n m}$, are a preferred tool for many theoretical and practical applications in geodesy, especially for the representation of the Earth's gravitational potential $V[36]$

$$
V(r, \theta, \lambda)=\frac{G M}{R_{E}}\left[\sum_{n=2}^{\infty} \sum_{m=0}^{n}\left(\frac{R_{E}}{r}\right)^{n+1}\left(c_{n m} \cos m \lambda+s_{n m} \sin m \lambda\right) \bar{P}_{n m}(\cos \theta)\right]
$$

where $G$ is the geocentric gravitational constant; $M$ is the mass of the Earth; $r, \theta, \lambda$ are the spherical coordinates: geocentric radius, co-latitude and longitude of the computation point, respectively; $P_{m n}(\cos \theta)$ is the fully normalized associated Legendre function; $\gamma$ is the normal gravity at point $(r, \theta, \lambda) ; N_{\max }$ is the maximum $S H$ degree of geopotential model applied. Therefore, most of the existing gravity field models 


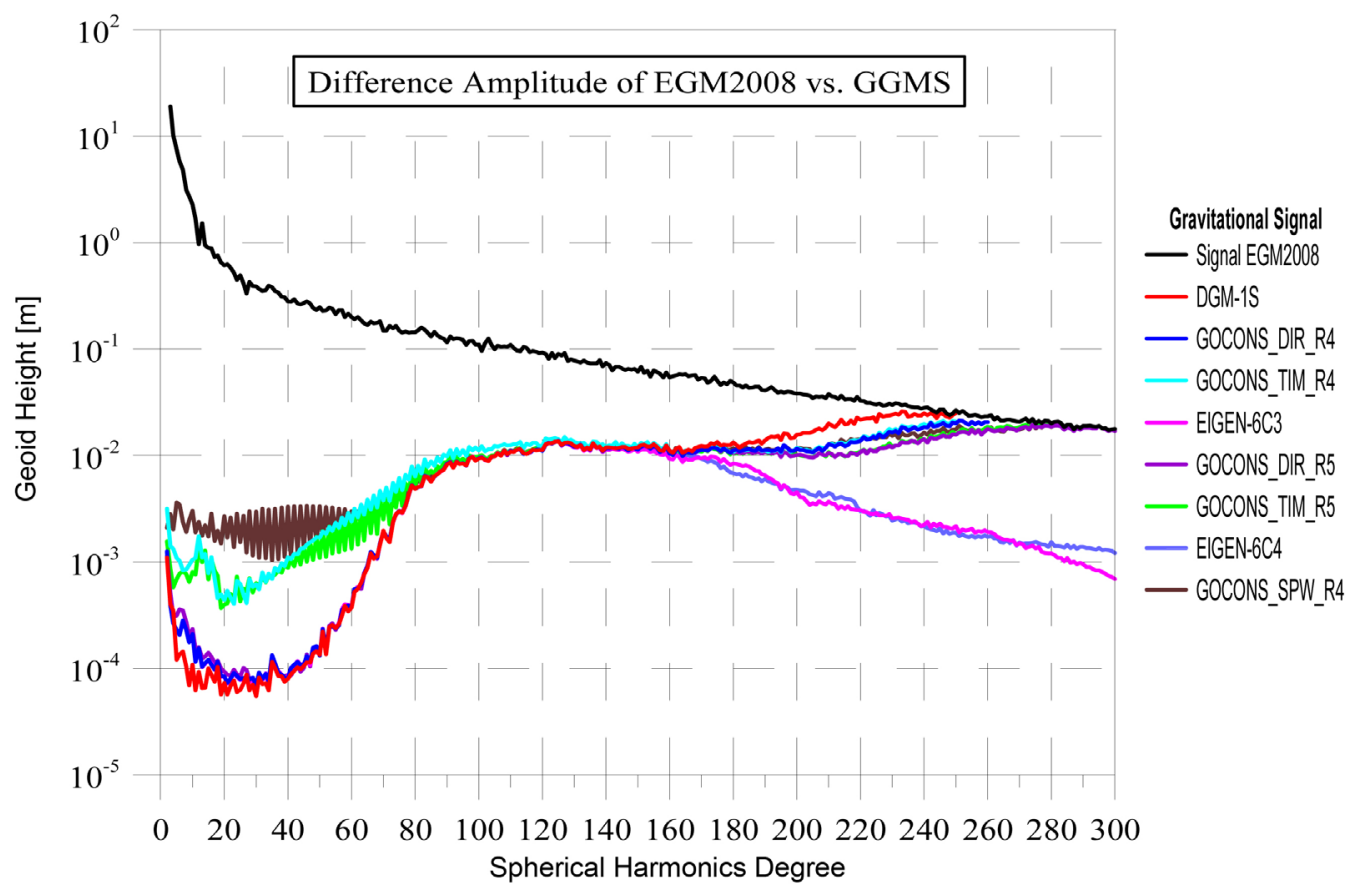

Figure 3. Difference degree variances in terms of geoid heights [m] between GOCE-based GGMs and EGM2008.

are formulated in terms of $S H$ coefficients. In the geodesy representation, the related quantities such as gravity anomalies $\Delta g$ and quasi geoid heights $\zeta$ computed with the following formulae ([37], p. 272):

$$
\begin{gathered}
\Delta g(r, \theta, \lambda)=\frac{G M}{r^{2}}\left[\sum_{n=2}^{N_{\max }}(n-1)\left(\frac{R_{E}}{r}\right)^{n} \sum_{m=0}^{n}\left(\Delta c_{n m} \cos m \lambda+\Delta s_{n m} \sin m \lambda\right) \bar{P}_{n m}(\cos \theta)\right] \\
\zeta(r, \theta, \lambda)=\frac{G M}{r \gamma}\left[\sum_{n=2}^{N_{\max }}\left(\frac{R_{E}}{r}\right)^{n} \sum_{m=0}^{n}\left(\Delta c_{n m} \cos m \lambda+\Delta s_{n m} \sin m \lambda\right) \bar{P}_{n m}(\cos \theta)\right]
\end{gathered}
$$

As seen from Figure 3, some points can be addressed here: 1) the GOCE-based direct solutions (DIR) outperform the time-wise (TIM) and space-wise (SPW) ones, particularly at the long spectrum of the gravity wavelength, where the observations of the Gravity Recovery And Climate Experiment (GRACE) mission contribute the DIR solutions. 2) Higher errors of the TIM models are provided at lower harmonics. The reason may be back to that no a-priori gravity information, neither as reference model, were considered within the processing strategies of the TIM releases. However, the TIM releases provide outperformed accuracy than the DIR solutions in such cases (cf. releases 4 and 5 of TIM and DIR) at the short wavelength of the gravity spectrum due to the contribution of the satellite gravity gradiometer (SGG) only measurements. 3) The space-wise solution, SPW_R4 model, provides high variances at lower harmonics because EGM2008 was used to model the degree variances and to calibrate the error of the estimated gravitational potential along track. 4) The Eigen-6C4 solution has the least variances especially at higher spherical harmonic degrees because of the contri- 
bution of EGM2008 altimetry/terrestrial data into Eigen-6C series (Eigen-6C3stat and $-6 \mathrm{C} 4)$.

On a regional scale, the spectral consistency between GOCE-based GGMs and EGM2008 should be taken in to consideration toward a reliable comparison. This is due to the fact that GOCE-based GGMs differ in resolution, besides their processing strategies with respect to EGM2008. Accordingly, the solution of each model has been restricted from SH d/o 2 up to $N_{\max }=100,110, \cdots, 270,280$ (10 d/o step) on grids from $1.8^{\circ} \times$ $1.8^{\circ}, 1.64^{\circ} \times 1.64^{\circ} \cdots 0.66^{\circ} \times 0.66^{\circ}, 0.64^{\circ} \times 0.64^{\circ}$, respectively. We have focused in our study only on SH degrees from 100 to 280 for two main reasons; first to examine which of GOCE-based GGMs approximate closely the gravity field over Egypt especially at the medium to short wavelength of the gravity spectral bands, where the contribution of GOCE is significant. Second, to investigate at which spectral bands they deliver improved information.

\section{Comparison of GOCE-Based GGMs with the EGM2008 over Egypt}

The GOCE-based GGMs specified in section 3 have been chosen as a subject for the evaluation over the study area of Egypt using EGM2008. Since the investigated GGMs differ in their data processing methodology and spatial resolution as well (see section 1), the spectral consistency between them should be taken into account. In other words, the GOCE-based GGMs and EGM2008 are examined at the same SH spectral bands. Thus, each model has been restricted from SH d/o 2 up to $N_{\text {max }}=100,110, \cdots, 290,300$ $\left(10 \mathrm{~d} / \mathrm{o}\right.$ step), on grids from $1.8^{\circ} \times 1.8^{\circ}, 1.64^{\circ} \times 1.64^{\circ} \cdots 0.62^{\circ} \times 0.62^{\circ}, 0.6^{\circ} \times 0.6^{\circ}$, respectively.

Figure 4 and Figure 5 show the standard deviations (std.) of differences between the free-air gravity anomalies $\delta \Delta g$ (Equation 9) and quasi geoid heights $\delta \Delta \zeta$ (Equation 10) obtained from GOCE-based GGMs and the corresponding ones from EGM2008 at the same maximum $\mathrm{d} / \mathrm{o}$ of their spherical harmonics:

$$
\begin{gathered}
\delta \Delta g=\left.\Delta g_{\mathrm{GOCE}}\right|_{2} ^{N_{\max }}-\left.\Delta g_{\mathrm{EGM} 2008}\right|_{2} ^{N_{\max }} \\
\delta \Delta \zeta=\left.\Delta \zeta_{\mathrm{GOCE}}\right|_{2} ^{N_{\max }}-\left.\Delta \zeta_{\mathrm{EGM} 2008}\right|_{2} ^{N_{\max }}
\end{gathered}
$$

The results, represented in Figure 4 and Figure 5, indicate that beside GOCE data the contribution of terrestrial/altimetry data to the Eigen-6C3 and Eigen-6C4 are clearly visible from $\mathrm{d} / \mathrm{o} 170$ onward. This is because the reason mentioned in section 3 that Eigen-6C series have been developed with the use of altimetry/terrestrial data obtained from EGM2008 and DUT12 GGM. From d/o 200 onward, the std. have increased rapidly for all the GOCE-based GGMs solutions, since the coefficients beyond d/o 180 200 were estimated with the use of Kaula's rule [4] [5] [38] and because above d/o 200 noise starts to dominate signals [39].

Except that, the contribution of GOCE at higher harmonics is clearly visible. For instance, comparing the DIR_R4 with DIR_R5 of Figure 4 at the same spectral domain (e.g. SH d/o 210), we find that the former model estimates free-air gravity anomalies as 


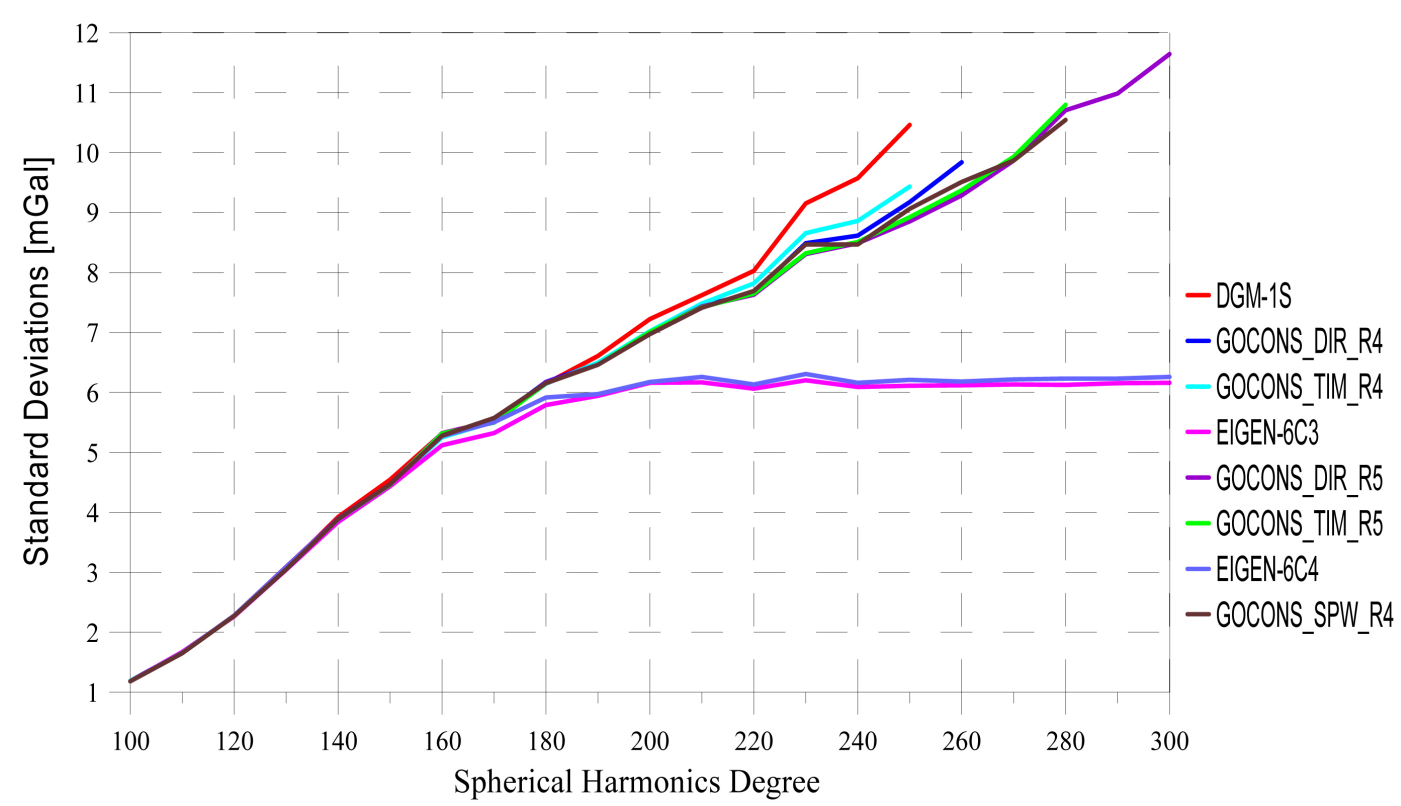

Figure 4. Standard deviations of the differences between gravity anomalies in [mGal] from the investigated GOCE-based GGMs $\left(N_{\max }=100,110,120, \cdots, 300\right)$ and the corresponding ones from EGM2008 truncated at the same $N_{\max }$.

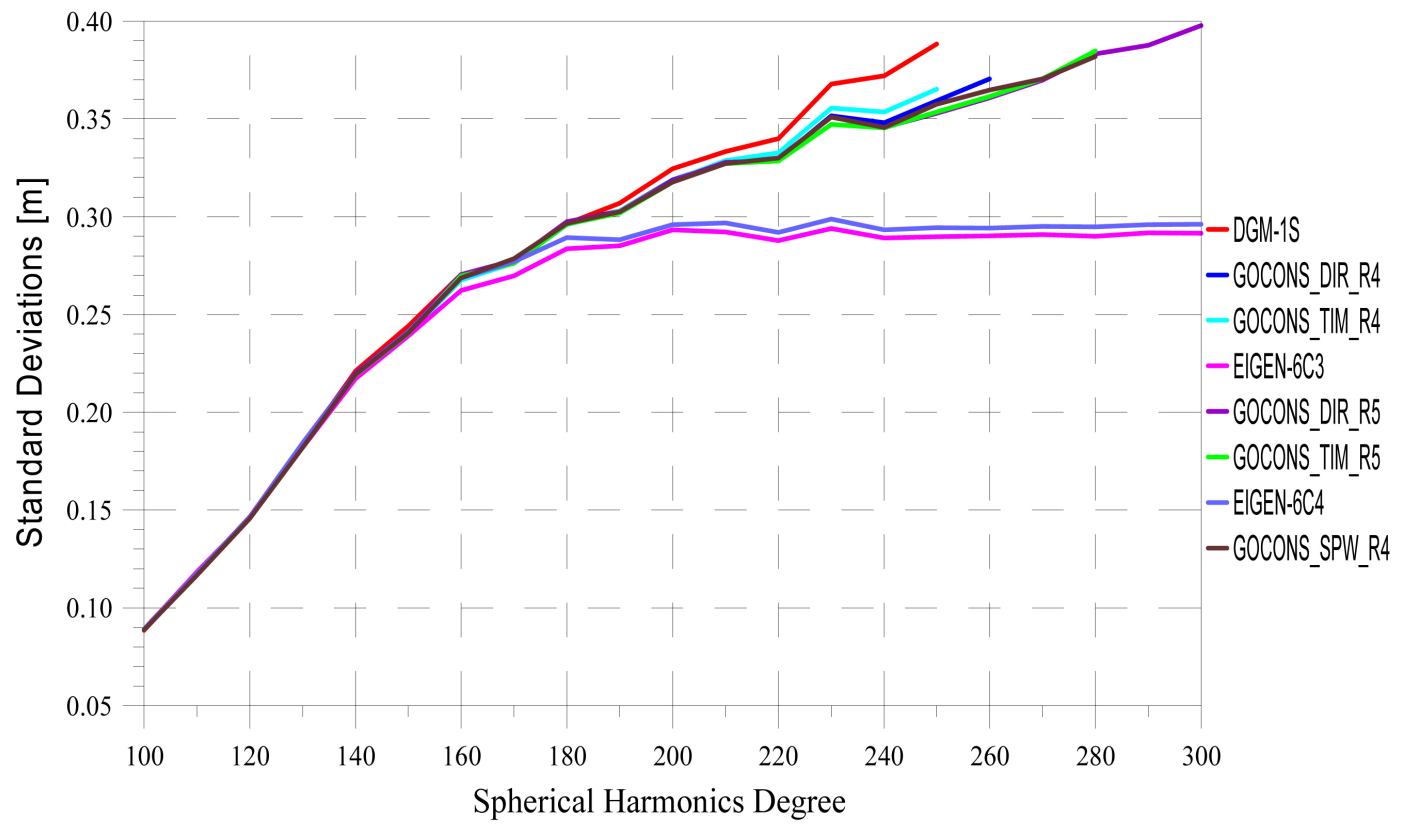

Figure 5. Standard deviations of the differences between quasi geoid heights in $[\mathrm{m}]$ from the investigated GOCE- based GGMs $\left(N_{\max }=100,110,120, \cdots, 300\right)$ and the corresponding ones from EGM2008 truncated at the same $N_{\max }$.

well as quasi geoid heights better than the latter one. From d/o 200 onward, the std. for each of the relatively recent GOCE-based GGM releases outperform the former release of the same type. This can be obviously seen from Table 2, which shows the statistics of 
Table 2. Statistics of the differences between free-air gravity anomalies in $\mathrm{mGal}$ (left side) and quasi geoid heights in cm (right side) obtained from GOCE-based GGMs ( $N_{\max }=100,110,120, \cdots, 300$ ) and the corresponding ones calculated from EGM2008.

\begin{tabular}{ccccccc}
\hline Statistics & $\delta \Delta g$ & $\delta \Delta g$ & $\delta \Delta g$ & $\delta \Delta \zeta$ & $\delta \Delta \zeta$ & $\delta \Delta \zeta$ \\
GGMs & $\begin{array}{c}\left(N_{\max }=200\right) \\
\text { STD. [mGal] }\end{array}$ & $\begin{array}{c}\left(N_{\max }=240\right) \\
\text { STD. [mGal] }\end{array}$ & $\begin{array}{c}\left(N_{\max }=280\right) \\
\text { STD. [mGal] }\end{array}$ & $\begin{array}{c}\left.N_{\max }=200\right) \\
\text { STD. [cm] }\end{array}$ & $\begin{array}{c}\left(N_{\max }=240\right) \\
\text { STD. [cm] }\end{array}$ & $\begin{array}{c}\left(N_{\max }=280\right) \\
\text { STD. [cm] }\end{array}$ \\
\hline DGM-1s & 7.23 & 9.57 & ---- & 32.46 & 37.19 & ---- \\
DIR_R4 & 7.02 & 8.61 & ---- & 31.88 & 34.82 & ---- \\
TIM_R4 & 7.02 & 8.86 & ---- & 31.84 & 35.37 & $-\cdots$ \\
Eigen-6C3 & 6.16 & 6.09 & 6.13 & 29.32 & 28.93 & 28.99 \\
DIR_R5 & 6.99 & 8.49 & 10.70 & 31.83 & 34.57 & 38.33 \\
TIM_R5 & 7.01 & 8.51 & 10.80 & 31.78 & 34.55 & 38.49 \\
Eigen-6C4 & 6.17 & 6.16 & 6.23 & 29.60 & 29.32 & 29.48 \\
SPW_R4 & 6.98 & 8.47 & 10.55 & 31.77 & 34.56 & 38.18 \\
\hline
\end{tabular}

the differences in terms of standard deviations between free-air gravity anomalies $\delta \Delta g$ and quasi geoid heights $\delta \Delta \zeta$. The std. differences of quasi geoid heights and free-air gravity anomalies between GOCE-based GGMs and EGM2008 are at the level of about $29-32 \mathrm{~cm}$ and $6-7 \mathrm{mGal}$ for d/o 200, respectively, of about $28-37 \mathrm{~cm}$ and $6-9 \mathrm{mGal}$ for d/o 240 and of about $38 \mathrm{~cm}$ and $10.7 \mathrm{mGal}$ for d/o 280 .

\section{Comparison of GOCE-Based GGMs with Ground-Based Data over Egypt}

To provide a reliable external validation and accuracy assessment of the investigated GOCE-based GGMs, the use of ground-truth data (terrestrial gravity and/or GPS/levelling) is quite important. In the following, the validation strategies of both free-air gravity anomalies and quasi geoid heights obtained from GOCE-based GGMs using the corresponding ones obtained from terrestrial gravity and GPS/levelling data over Egypt region are discussed.

\subsection{Comparison of GOCE-Based GGMs with Terrestrial Gravity Data}

Regarding the comparison between gravity anomalies as derived from the GOCE-based GGMs and those obtained from terrestrial data, the different spectral consistency is an important issue that should be taken into consideration. Spectral consistency means that we add the contribution of the short and very-short wavelength gravity signals beyond the applied maximum degree of GOCE-based GGMs. For this purpose, we add the contribution of short and very-short gravity signals using EGM2008 and the residual terrain modeling procedure as computed from the Terrain Correction TC program [40], respectively.

This is due to the fact that gravity anomalies provided by the GOCE-based GGMs have a finite wavelength range of the gravity spectrum, whereas gravity anomalies ob- 
tained from terrestrial measurements contain "theoretically" the full spectral information of the gravity field, particularly the high- and very-high-frequency ranges, which are not included in the GGMs as described in Figure 6.

Numerous approaches were developed to remove the spectral inconsistency between both datasets in order to get a reliable comparison, e.g. the spectral enhancement method [16] [41], the use of Gaussian "low-pass" filtering [17], and by means of orbit residuals and geoid comparisons [14]. Two approaches have been implemented in this study to compare between the GOCE- and ground-based gravity anomalies and geoid heights. The first method uses the spectral enhancement method (SEM) to compensate the high frequency gravity signal that is not included in GOCE-based GGMs. In the second method, a simple low-pass filtering is applied. In the following, both methods are discussed.

In [16], the spectral gap between GOCE-based GGMs and terrestrial observations is bridged partially by a combination of: 1) the high-degree spectral bands of EGM2008 up to d/o 2190, and 2) the omitted gravity signal from d/o 2190 onward estimated from the topography data, i.e. from SRTM30_PLUS (Shuttle Radar Topography Mission of spatial resolution about $\sim 900 \mathrm{~m}, 30$ arc-sec), using the RTM method (see [40]). Accordingly, free-air anomalies from GOCE-based GGMs, $\Delta g_{\mathrm{GOCE}}$, have been computed over the 930 stations in the medium and short spectrum of gravity wavelength of $d / o$ 100, $110,120 \cdots 300$ (with 10 step). We should mention here that based on the results indicated in section 4 (Table 2), we focused on the last release of GOCE-based GGMS of type DIR_R5, TIM_R5, SPW_R4, where the contribution of GOCE observations is clearly visible in addition to the Eigen-6C4.

The remaining gravity signals in the spectral range from 101, 111, 121 $\cdots 301$ up to 2190 were compensated from EGM2008 $\left(\Delta g_{\mathrm{EGM} 2008}\right)$. The RTM omission error estimates (i.e. from 2190 onward) as implied by the residual topography $\left(\Delta g_{\text {Tоро }}\right)$ has been determined using the TC program of [40]. The summation $\Delta g_{\mathrm{GGM}}$ reads then

$$
\Delta g_{\mathrm{GGM}}=\left.\Delta g_{\mathrm{GOCE}}\right|_{2} ^{N_{\max }}+\left.\Delta g_{\mathrm{EGM} 2008}\right|_{N_{\max }+1} ^{2190}+\Delta g_{\mathrm{TOPO}}
$$

The term $\Delta g_{\mathrm{GGM}}$ possess almost the full spectral power and can be now compared with terrestrial free-air gravity.

Anomalies $\left(\Delta g_{\text {Terr }}\right)$ :

$$
\delta \Delta g_{\mathrm{SEM}}=\Delta g_{\mathrm{Terr}}-\Delta g_{\mathrm{GGM}}
$$

Figure 7 shows the standard deviations of differences $\left(\delta \Delta g_{\text {SEM }}\right)$ between the terrestrial

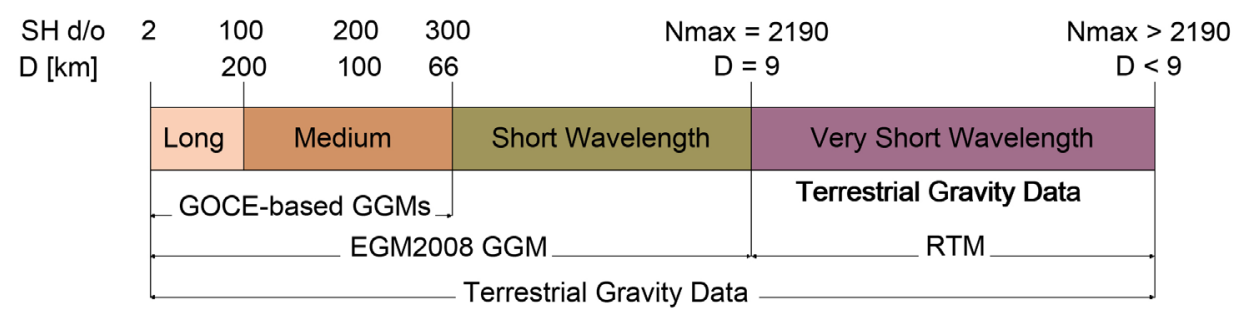

Figure 6. Spectral range (SH d/o) and spatial resolution (D in km) for satellite and terrestrial data. 


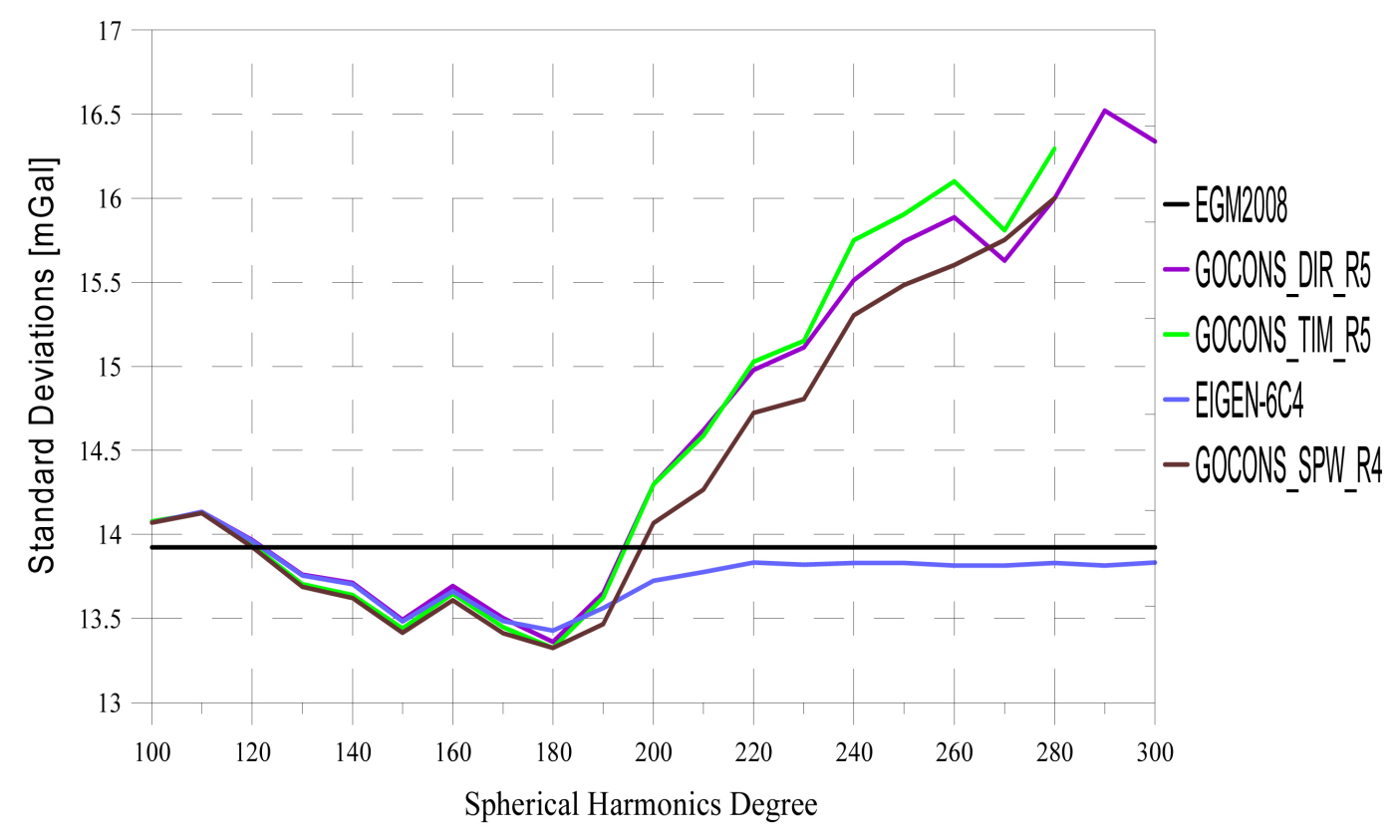

Figure 7. Standard deviations of the differences between terrestrial free-air gravity anomalies [mGal] and the corresponding ones from GOCE-based GGMs extended by the EGM2008 and RTM over Egypt.

free-air gravity anomalies and the corresponding ones from GOCE-based GGMs, while the std. are indicated in Table 3. One can clearly see that the gravity anomalies as derived from the GOCE-based GGMs indicates slightly better fit to the terrestrial data than EGM2008 over Egypt. The improvement is about $0.61 \mathrm{mGal}$ in terms of standard deviation of the differences. Moreover, the contribution of the SPW_R4 extended with EGM2008 and RTM based on Equation 11 is obviously seen from SH d/o 120 up to d/o 200. We can infer from Tables 1-3 that the GOCE-based GGM of type SPW_R4 are the appropriated satellite model that approximate the gravity field over Egypt region than those of type DIR_R5 and TIM_R5. Accordingly, when modeling the local quasi-geoid heights over Egypt, the SPW_R4 is strongly suggested by subtracting its wavelength spectrum up to $S H$ d/o 200, from the terrestrial gravity anomalies. On a spatial domain, the outcome of Equations (11)-(12) is represented in Figure 8 as follow: Figure 8(a) free-air anomalies from the SPW_R4 GOCE-based GGM $\left(\Delta g_{\text {GOCE }}\right)$ up to SH d/o 200, Figure 8(b) the remaining short gravity signal from 201 up to 2190 from EGM2008 $\left(\Delta g_{\mathrm{EGM} 2008}\right)$, Figure $8(\mathrm{c})$ the omission error estimates based on RTM data $\left(\Delta g_{\mathrm{TOPO}}\right)$, Figure $8(\mathrm{~d})$ the summation of Figures $8(\mathrm{a})$-(c) (i.e. $\Delta g_{\mathrm{GGM}}$ ), Figure $8(\mathrm{e})$ terrestrial free air anomalies for the 930 sites $\left(\Delta g_{\text {Terr }}\right)$ and Figure 8(f) the difference between $8(\mathrm{~d})$ and $8(\mathrm{e})\left(\delta \Delta g_{\text {SEM }}\right)$.

In the second approach, a simple low pass filter (LPF) based on reciprocal distances from the computation point was applied, following [24], for generating a grid of terrestrial free-air gravity anomalies in order to mimic the spatial resolution of the investigated GOCE-based GGMs at SH d/o $200(\approx 100 \mathrm{~km})$. The weighting function W of this low pass filter is expressed as follows. 
Table 3. Statistics of the std. differences between terrestrial free-air gravity anomalies and GOCEbased GGMs at SH d/o 200 and 240.

\begin{tabular}{ccccccccc}
\hline $\begin{array}{c}\text { Statistics } \\
\text { GGMs }\end{array}$ & \multicolumn{3}{c}{$\delta \Delta g_{\text {SEM }}\left(N_{\max }=200\right)$} & & & $\delta \Delta g_{\text {SEM }}\left(N_{\text {max }}=240\right)$ & \\
\hline & $\begin{array}{c}\text { STD. } \\
{[\mathrm{mGal}]}\end{array}$ & $\begin{array}{c}\text { Mean } \\
{[\mathrm{mGal}]}\end{array}$ & $\begin{array}{c}\text { Min } \\
{[\mathrm{mGal}]}\end{array}$ & $\begin{array}{c}\text { Max } \\
{[\mathrm{mGal}]}\end{array}$ & $\begin{array}{c}\text { STD. } \\
{[\mathrm{mGal}]}\end{array}$ & $\begin{array}{c}\text { Mean } \\
{[\mathrm{mGal}]}\end{array}$ & $\begin{array}{c}\text { Min } \\
{[\mathrm{mGal}]}\end{array}$ & $\begin{array}{c}\text { Max } \\
{[\mathrm{mGal}]}\end{array}$ \\
\hline DIR_R5 & 14.29 & 1.72 & -71.02 & 52.04 & 15.51 & 1.618 & -78.46 & 56.645 \\
TIM_R5 & 14.29 & 1.82 & -70.11 & 51.68 & 15.74 & 1.69 & -78.34 & 55.97 \\
Eigen-6C4 & 13.77 & 1.33 & -71.95 & 50.82 & 13.82 & 1.32 & -72.11 & 50.68 \\
SPW_R4 & 14.06 & 1.63 & -69.34 & 50.23 & 15.30 & 1.33 & -76.75 & 51.31 \\
EGM08 & 13.92 & 2.19 & -76.15 & 47.08 & 13.92 & 2.19 & -76.15 & 47.08 \\
\hline
\end{tabular}

$$
W=\left\{\begin{array}{lc}
W_{c} & \text { if } \Delta x_{i}=0 \text { and } \Delta y_{i}=0 \\
\left(\frac{1}{\Delta x_{i}^{2}+\Delta y_{i}^{2}}\right)^{p / 2} & \text { otherwise }
\end{array}\right.
$$

where $x_{i}, y_{i}$ are the components of the distance from the computation point in $x$, and $y$ directions, respectively. In this study, the central weight $W_{c}$ and the power $p$ were both fixed to 1 ; the maximum distance from the computation point was fixed at a spatial scale of $100 \mathrm{~km}$.

The resulting terrestrial gravity signals after applying the low pass filter are presented in Figure 9.

The terrestrial free-air gravity anomalies $\Delta g_{\mathrm{LPF}}$ at the location of gravity stations (Figure 1) were then extrapolated from the filtered grid as shown in Figure 9. The differences $\delta \Delta g_{\mathrm{LPF}}$ between filtered terrestrial free-air gravity anomalies $\left(\Delta g_{\mathrm{LPF}}\right)$ and the corresponding ones $\left(\Delta g_{\mathrm{GGM}}\right)$ computed from GOCE-based GGMs were obtained as follows

$$
\delta \Delta g_{\mathrm{LPF}}=\Delta g_{\mathrm{LPF}}-\Delta g_{\mathrm{GGM}}
$$

Table 4 shows the std. of the differences between free-air gravity anomalies derived from GOCE-based GGMs and the filtered ones obtained from terrestrial gravity data. The results indicate that the std. of the differences between free-air gravity anomalies from GOCE-based GGMs and filtered terrestrial gravity data are within the range of $11.96-12.17 \mathrm{mGal}$. It should be pointed out here that the fit of all GOCE-based GGMs and EGM08 to the terrestrial gravity anomalies is similar when using the SEM approach, whereas in case of using the LPF approach, GOCE-based GGMs exhibit improvement with respect to EGM08 by about $0.69 \mathrm{mGal}$ in terms of the std. of their differences. The use of LPF approach results in about $14 \%$ reduction in std. of the differences for the investigated GOCE-based GGMs.

We can conclude here that EGM08 is not accurate enough for modelling higher frequency gravity signals (e.g. d/o 201 - 2190) over EGYPT, since it is based on fill-in observations over that area. The means of the differences slightly increased (by about 8.90 $\mathrm{mGal}$ ) when applying low pass filter approach. 

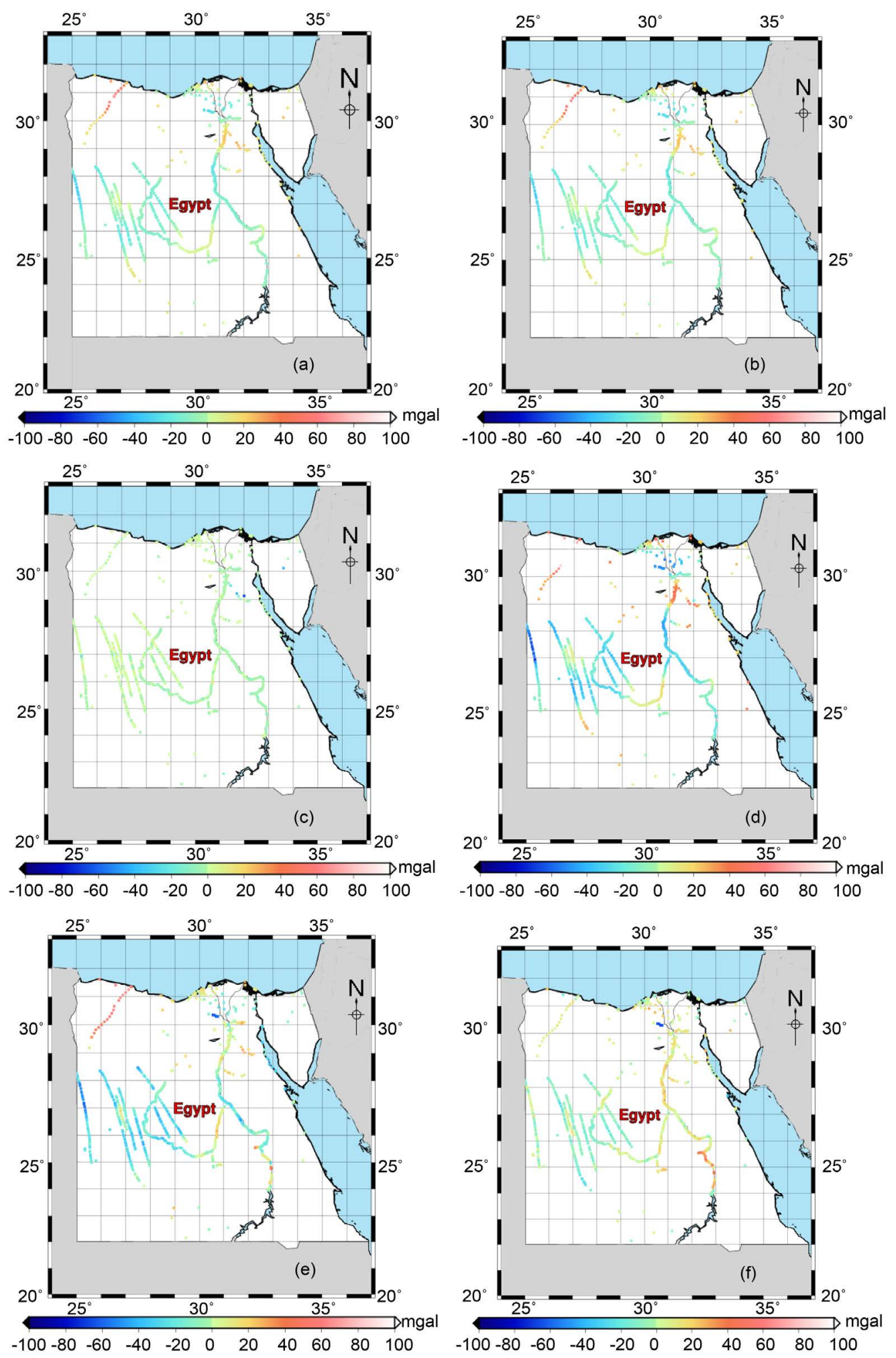

Figure 8. Free-air gravity anomalies in [mGal] of (a) the SPW_R4 GOCE-based GGM up to SH d/o 200, (b) the remained gravity signal from 201 up to 2190 from EGM2008, (c) the omission error estimates based on RTM, (d) the summation of (a) to (c), (e) terrestrial free air anomalies and (f) the difference between (d) and (e). 


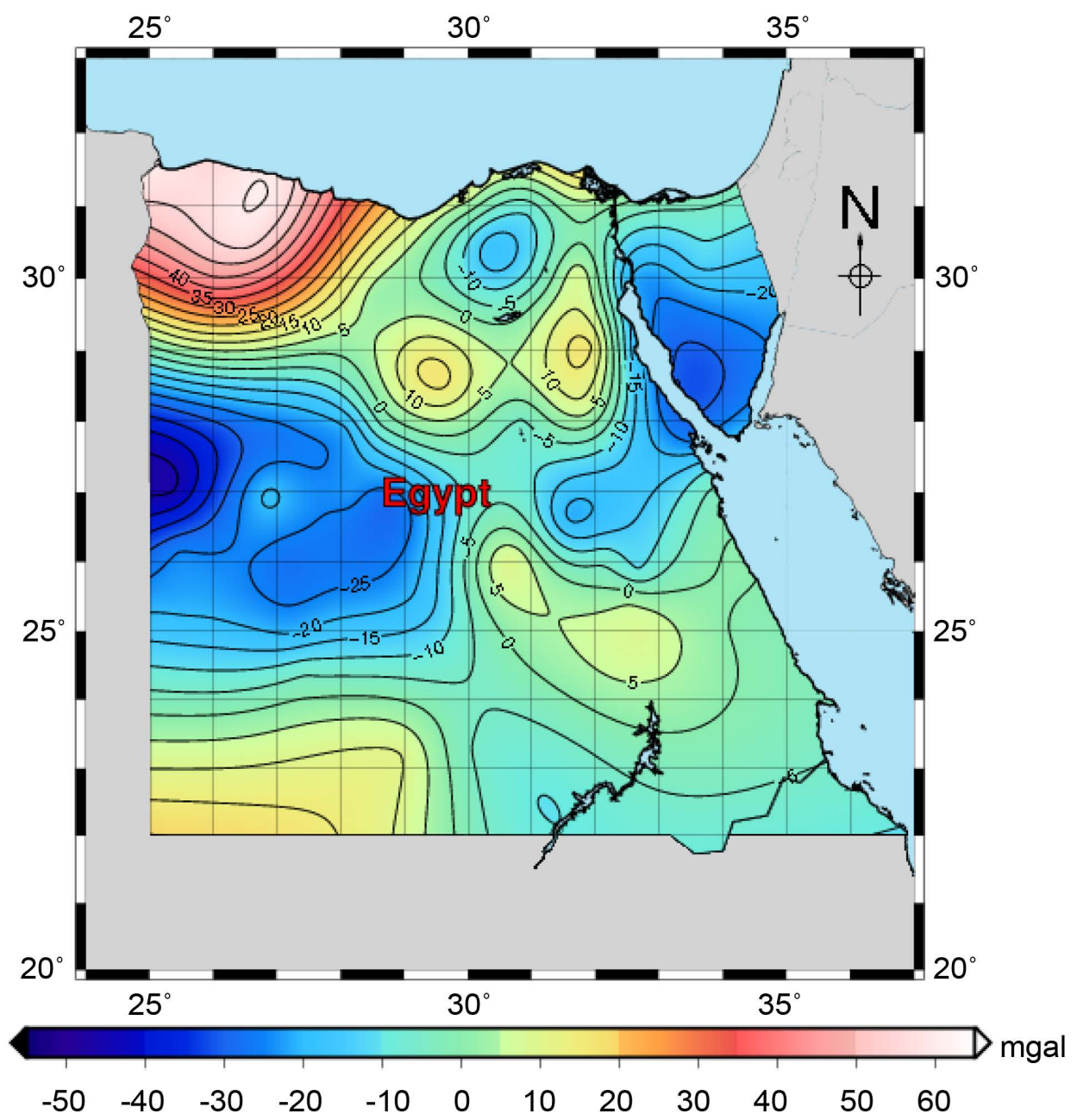

Figure 9. The terrestrial gravity signals after applying the low pass filter.

Table 4. Statistics of the std. of the differences between terrestrial free-air gravity anomalies after LPF approach and GOCE-based GGMs at SH d/o 200.

\begin{tabular}{ccccc}
\hline $\begin{array}{c}\text { Statistics } \\
\text { GGMs }\end{array}$ & & $\delta \Delta g_{\text {LPF }}\left(N_{\max }=200\right)$ & \\
\hline & STD. [mGal] & Mean [mGal] & Min [mGal] & Max [mGal] \\
\hline DIR_R5 & 12.10 & -7.19 & -41.21 & 44.64 \\
TIM_R5 & 12.17 & -7.10 & -41.39 & 44.40 \\
Eigen-6C4 & 11.96 & -7.46 & -42.43 & 44.87 \\
SPW_R4 & 12.09 & -7.21 & -41.69 & 44.36 \\
EGM08 & 12.77 & -6.66 & -48.72 & 45.12 \\
\hline
\end{tabular}

\subsection{Comparison of GOCE-Based GGMs with GPS/Levelling Data}

Here the quasi geoid heights derived from GOCE-based GGMs have been validated with the corresponding ones of ground-based GPS/levelling date on different spectral 
bands following the same procedures described in section 5.1. Consequently, the term $\Delta \zeta_{\mathrm{GOCE}(\mathrm{point})}$ was compensated by adding the term $\Delta \zeta_{\mathrm{EGM} 2008(\text { point })}$ that represents the high frequency information from EGM2008 up to d/o 2190. Moreover, the term $\Delta \zeta_{\text {RTM }}$ which depicts the very high frequency gravity signal beyond SH d/o 2190 was also added. It is expressed in planar approximation as (Forsberg 1984).

The complete formulae can be written as follows spectral enhancement method [16] [41]:

$$
\Delta \zeta_{\mathrm{GGM}}=\left.\Delta \zeta_{\mathrm{GOCE}}\right|_{2} ^{N_{\max }}+\left.\Delta \zeta_{\mathrm{EGM} 2008}\right|_{N_{\max }+1} ^{2190}+\Delta \zeta_{\mathrm{RTM}}
$$

Now, the term $\Delta \zeta_{\mathrm{GGM}}$ possess almost the full spectral domain and can be compared with the quasi geoid heights from GPS/levelling data $\left(\Delta \zeta_{\mathrm{GPS} / \text { levelling }}\right)$ :

$$
\delta \Delta \zeta=\Delta \zeta_{\mathrm{GPS} / \mathrm{Levelling}}-\Delta \zeta_{\mathrm{GGM}}
$$

The differences $(\delta \Delta \zeta)$ in terms of standard deviations are shown in Figure 10 and Table 5. The least differences are provided by the SPW_R4 from SH d/o 190 up to d/o $\sim 280$ (from $43.2 \mathrm{~cm}$ to $37.9 \mathrm{~cm}$, respectively). Whereas, the std. of geoid height differences between the GPS/levelling and EGM2008 ( $\left.N_{\max }=2190\right)$ are about $53.8 \mathrm{~cm}$.

Obviously, it can be concluded that, implementing the spectral enhancement method helped much in improving the quality of GOCE-based GGMs. A considerable reduction of about $29.55 \%$ (i.e. improvement factor of about one third) in terms of standard deviations of quasi geoid heights differences is observed after compensating the medium/ short and very-short wavelength gravity signal using EGM2008 and RTM.

\section{Fitting of Geoid Models from GOCE-Based GGMs to GPS/Levelling}

The results indicated in section 5.2 are represented in terms of std. of the differences between GPS/levelling data and GOCE-based GGMs. However, it should be noted that the mean values of these differences are at the level of $0.30 \mathrm{~m}$. This can be interpreted as a bias which may be attributed to the offset between two equipotential surfaces formed by the gravimetric geoid model derived by GOCE and Egypt vertical datum (NED-95, see section 2.2.2).

In order to minimize this bias and to determine a better fit of geoid models determined from GOCE-based GGMs and the GPS/levelling data over Egypt, we have applied the parameter transformation models of corrector surface similar to [24] and [25]. Based on this, three types of parameter transformation models have been investigated; the four-, five- and seven-parameter transformation models. The four-parameter transformation model reads [36]:

$$
\Delta \zeta=\cos \varphi_{i} \cos \lambda_{i} \cdot x_{1}+\cos \varphi_{i} \sin \lambda_{i} \cdot x_{2}+\sin \varphi_{i} \cdot x_{3}+x_{4}+v_{i}
$$

While the five-parameter transformation model reads [42]:

$$
\Delta \zeta=\cos \varphi_{i} \cos \lambda_{i} \cdot x_{1}+\cos \varphi_{i} \sin \lambda_{i} \cdot x_{2}+\sin \varphi_{i} \cdot x_{3}+\sin ^{2} \varphi_{i} x_{4}+x_{5}+v_{i}
$$

And the seven-parameter transformation model reads e.g. [43]: 


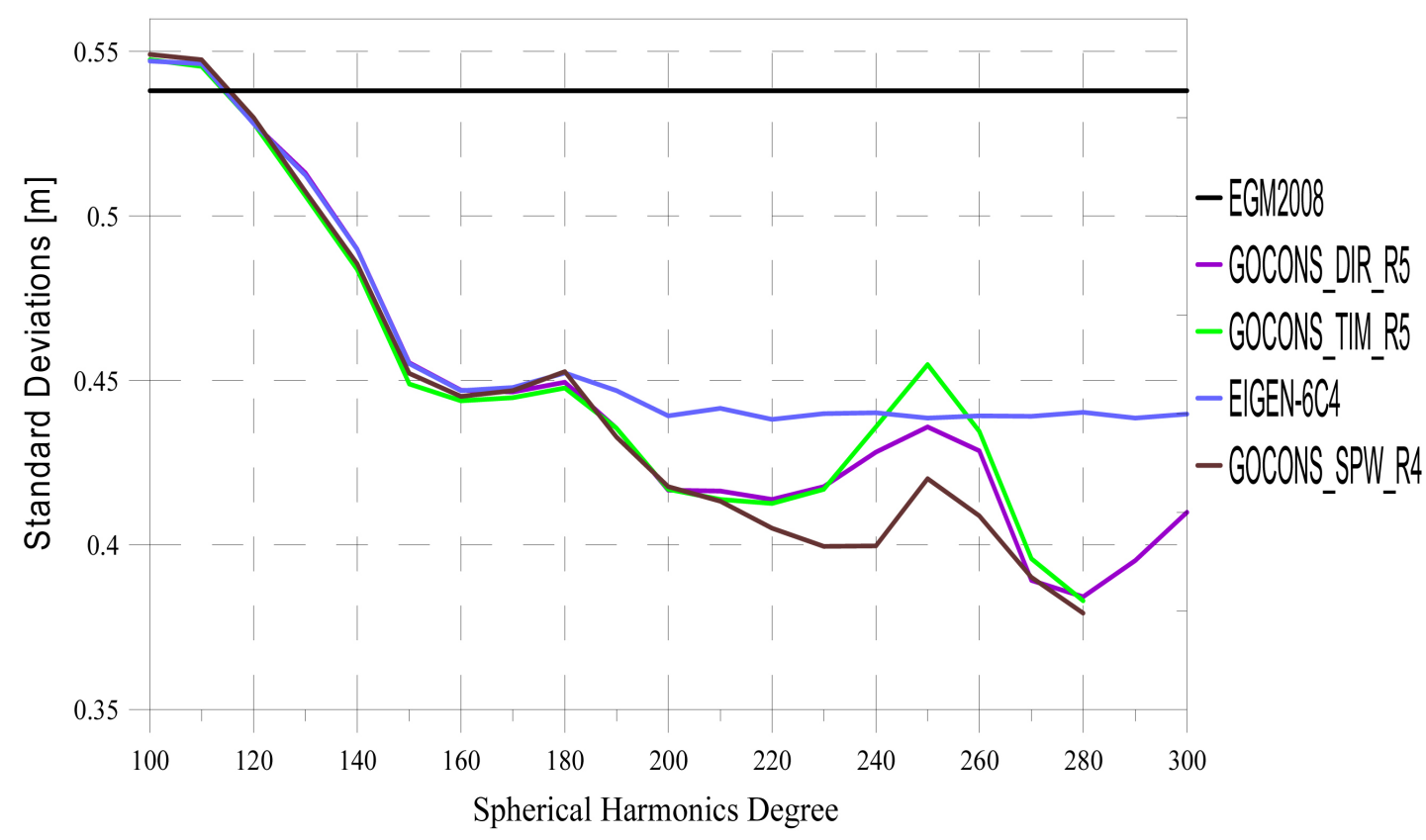

Figure 10. Standard deviations of the differences between quasi geoid heights [meters] from the terrestrial GPS/ levelling and GOCE-based GGMs extended by EGM2008 and RTM over Egypt.

$$
\begin{aligned}
\Delta \zeta= & \cos \varphi_{i} \cos \lambda_{i} \cdot x_{1}+\cos \varphi_{i} \sin \lambda_{i} \cdot x_{2}+\sin \varphi_{i} \cdot x_{3}+\frac{\cos \varphi_{i} \sin \varphi_{i} \cos \lambda_{i}}{\sqrt{1-e^{2} \sin ^{2} \varphi_{i}}} \cdot x_{4} \\
& +\frac{\cos \varphi_{i} \sin \varphi_{i} \sin \lambda_{i}}{\sqrt{1-e^{2} \sin ^{2} \varphi_{i}}} \cdot x_{5}+\frac{\sin ^{2} \varphi_{i}}{\sqrt{1-e^{2} \sin ^{2} \varphi_{i}}} \cdot x_{6}+x_{7}+v_{i}
\end{aligned}
$$

where $x_{i}=1,2, \cdots, 7$ are the transformation parameters between two datums; $\left(\varphi_{i}, \lambda_{i}\right)$ are the latitude and longitude of the point; $v_{i}$ is the residual of random noise term and $e$ is the ellipsoid eccentricity.

Table 6 gives the statistics of the differences between quasi geoid heights [m] as obtained from GPS/levelling data and the corresponding of GOCE-based GGMs of types DIR_R5, TIM_R5 and SPW_R4 before and after removing the biases effect applying Equations 17-19. The results presented in Table 6 indicate that applying the 4-, 5-, and 7-parameter transformation models removes the systematic error (mean values in $\mathrm{Ta}$ ble 6). The assessed accuracy of quasi geoid heights differences in terms of std. after fitting gravimetric geoid models obtained from the GGMs investigated to the corresponding ones from GPS/levelling data is at the level of about $32 \mathrm{~cm}$. Table 6 indicates that the difference among the three applied transformation models in terms of their resulting statistics provide consistent results. This may indicate that practically all transformation models implemented in this study are suitable for fitting the gravimetric geoid model to the geometrical one obtained from GPS/levelling data.

\section{Conclusion}

This paper investigated the gravity field solutions in terms of free-air anomalies and 
Table 5. Statistics of the differences between GPS/levelling and GOCE-based GGMs at SH d/o 200 and 240.

\begin{tabular}{ccccccccc}
\hline $\begin{array}{c}\text { Statistics } \\
\text { GGMs }\end{array}$ & \multicolumn{3}{c}{$\delta \Delta \zeta_{\text {SEM }}\left(N_{\max }=200\right)$} & \multicolumn{5}{c}{$\delta \Delta \zeta_{\text {SEM }}\left(N_{\max }=240\right)$} \\
\hline & STD. [m] & $\operatorname{Mean}[\mathrm{m}]$ & $\operatorname{Min}[\mathrm{m}]$ & $\operatorname{Max}[\mathrm{m}]$ & STD. [m] & $\operatorname{Mean}[\mathrm{m}]$ & $\operatorname{Min}[\mathrm{m}]$ & $\operatorname{Max}[\mathrm{m}]$ \\
\hline DIR_R5 & 0.41 & 0.30 & -0.55 & 0.93 & 0.42 & 0.27 & -0.55 & 0.90 \\
TIM_R5 & 0.41 & 0.30 & -0.59 & 0.95 & 0.43 & 0.25 & -0.57 & 0.93 \\
Eigen-6C4 & 0.43 & 0.28 & -0.57 & 1.07 & 0.44 & 0.29 & -0.55 & 1.08 \\
SPW_R4 & 0.41 & 0.29 & -0.59 & 0.96 & 0.39 & 0.26 & -0.49 & 0.86 \\
\hline
\end{tabular}

Table 6. Statistics of the differences between quasi geoid heights [m] as derived from GPS/levelling data over Egypt and GOCE-based GGMs at SH d/o 200 extended by EGM2008 and RTM before and after applying 4-, 5-, and 7-parameter transformation models.

\begin{tabular}{|c|c|c|c|c|c|}
\hline $\begin{array}{c}\text { Transformation } \\
\text { model }\end{array}$ & Model (NSEM200-2190) & $\operatorname{Min}[\mathrm{m}]$ & $\operatorname{Max}[\mathrm{m}]$ & $\operatorname{Mean}[\mathrm{m}]$ & STD. $[\mathrm{m}]$ \\
\hline \multirow{5}{*}{ 节 } & EGM2008 & -0.778 & 1.5468 & 0.2768 & 0.538 \\
\hline & Eigen-6C4 & -0.5751 & 1.0718 & 0.2872 & 0.4393 \\
\hline & DIR_R5 & -0.5509 & 0.9378 & 0.3037 & 0.4166 \\
\hline & SPW_R4 & -0.5902 & 0.964 & 0.2976 & 0.4177 \\
\hline & TIM_R5 & -0.594 & 0.9511 & 0.3011 & 0.4169 \\
\hline \multirow{5}{*}{ 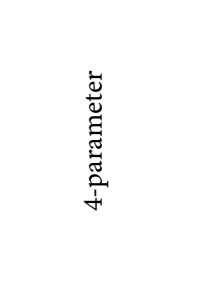 } & EGM2008 & -1.174 & 0.9256 & 0 & 0.4625 \\
\hline & Eigen-6C4 & -0.6189 & 0.6141 & 0 & 0.3408 \\
\hline & DIR_R5 & -0.6344 & 0.5676 & 0 & 0.3209 \\
\hline & SPW_R4 & -0.6677 & 0.5659 & 0 & 0.3231 \\
\hline & TIM_R5 & -0.6734 & 0.5561 & 0 & 0.3195 \\
\hline \multirow{5}{*}{ 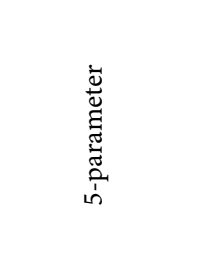 } & EGM2008 & -1.2311 & 0.8462 & 0 & 0.454 \\
\hline & Eigen-6C4 & -0.6787 & 0.5754 & 0 & 0.3281 \\
\hline & DIR_R5 & -0.681 & 0.5286 & 0 & 0.3072 \\
\hline & SPW_R4 & -0.7125 & 0.5285 & 0 & 0.3106 \\
\hline & TIM_R5 & -0.718 & 0.5189 & 0 & 0.307 \\
\hline \multirow{5}{*}{ 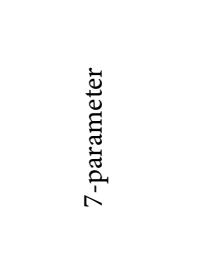 } & EGM2008 & -1.1938 & 0.6217 & 0 & 0.4252 \\
\hline & Eigen-6C4 & -0.6627 & 0.4478 & 0 & 0.3152 \\
\hline & DIR_R5 & -0.5939 & 0.4248 & 0 & 0.2963 \\
\hline & SPW_R4 & -0.6134 & 0.4348 & 0 & 0.3003 \\
\hline & TIM_R5 & -0.6142 & 0.418 & 0 & 0.2952 \\
\hline
\end{tabular}

quasi geoid heights as derived from the ground-based data and EGM2008 over the area of Egypt as a validation strategy of the GOCE-based GGMs. To validate the GOCEbased GGMs with ground-based data, two strategies have been applied: the spectral 
enhancement method and low-pass filter approach.

First, gravity functionals in term of free-air gravity anomalies and quasi geoid heights derived from GOCE-based GGMs were compared with the corresponding ones calculated from EGM2008 within the spectral range of the gravitational wavelength from $\mathrm{d} / \mathrm{o}$ 100 to 300. Our findings indicate some deviations of the quasi geoid heights and the free-air gravity anomalies obtained from GOCE-based GGMs and the corresponding ones from EGM2008 within the level of $29-32 \mathrm{~cm}$ and $6-7 \mathrm{mGal}$, respectively, at $\mathrm{SH}$ $\mathrm{d} / \mathrm{o} 200$, at the level of $28-37 \mathrm{~cm}$ and $6-9 \mathrm{mGal}$ at d/o 240 and at the level of $38 \mathrm{~cm}$ and $10.7 \mathrm{mGal}$ at $\mathrm{d} / \mathrm{o} 280$.

Second, free-air gravity anomalies obtained from GOCE-based GGMs were compared with the corresponding ones from terrestrial gravity data using the spectral enhancement method and low pass filter approach. In the former method, the free-air gravity anomalies obtained from GOCE-based GGMs agree with the corresponding terrestrial ones within the range of $14.1 \mathrm{mGal}$ at $S H \mathrm{~d} / \mathrm{o} 200$ providing slight improvement than EGM2008. This may back to poor coverage of gravity data in the area of Egypt and neighboring countries when developing EGM2008. In case of quasi geoid heights, a considerable reduction of about $29 \%$ in terms of standard deviations of quasi geoid heights differences is observed after implementing the spectral enhancement method. This means that the SEM strategy helps much in improving the quality of GOCE-based GGMs.

Regarding the low pass filter strategy, GOCE-based GGMs exhibit improvement with respect to EGM08 by about $0.69 \mathrm{mGal}$ in terms of the std. of their differences. The use of LPF approach results in about $14 \%$ reduction in std. of the differences for the investigated GOCE-based GGMs and the terrestrial gravity data.

Finally, we have applied three types of transformation models, namely four-, fiveand seven-parameters transformation model, in order to deal with the problem of datum inconsistencies between different datums of both datasets (i.e. geoid models obtained from GOCE-based GGMs and from GPS/levelling data). Our findings showed that the tree applied models exhibit all most consistent results. They suggest that the standard deviations of vertical datum over the Egyptian territory are at level of about 32 $\mathrm{cm}$.

To sum up, the GOCE-based SPW_R4 (up to $S H$ d/o 200) model is suggested to be used as a reference model when modeling the local quasi-geoid heights from the terrestrial gravity data, since it approximates the gravity field well over Egypt. This is a subject of our future consideration.

\section{Acknowledgements}

The spatial representations of the results have been plotted using the GMT5 (Generic Mapping Tools) software [44]. The computations of the topography potential effect in the geoid were carried out using the TC software and RTM procedure [40].

\section{References}

[1] ESA (1999) Gravity Field and Steady-State Ocean Circulation Explorer Mission. Report of 
European Space Agency for Mission Selection. The 4th Candidate Earth Explorer Core Missions, SP-1233, Nordwijk.

[2] Gruber, T., Rummel, R. and HPF Team (2014) GOCE Gravity Field Models-Overview and Performance Analysis. 5th International GOCE User Workshop, Paris, 25-29 November 2014.

[3] Rummel, R., Gruber, T. and Koop, R. (2004) High Level Processing Facility for GOCE: Products and Processing Strategy, 2nd International GOCE User Workshop "GOCE, The Geoid and Oceanography", Frascati, 8-10 March 2004, ESA SP-569.

[4] Pail, R., Bruinsma, S., Migliaccio, F., Förste, C., Goiginger, H., Schuh, W.-D., Höck, E., Reguzzoni, M., Brockmann, J.-M., Abrikosov, O., Veicherts, M., Fecher, T., Mayrhofer, R., Krasbutter, I., Sansò, F. and Tscherning, C.C., (2011) First GOCE Gravity Field Models Derived by Three Different Approaches. Journal of Geodesy, 85, 845-860.

https:/doi.org/10.1007/s00190-011-0467-x

[5] Bruinsma, S.L., Marty, J.C., Balmino, G., Biancale, R., Förste, C., Abrikosov, O. and Neumayer, H. (2010) GOCE Gravity Field Recovery by Means of the Direct Numerical Method. The ESA Living Planet Symposium, Bergen, 28 June-2 July 2010.

[6] Pail, R., Goiginger, H., Mayrhofer, R., Schuh, W.-D., Brockmann, J.M., Krasbutter, I., Hoeck, E. and Fecher, T. (2010) GOCE Gravity Field Model Derived from Orbit and Gradiometry Data Applying the Time-Wise Method. The ESA Living Planet Symposium, Bergen, 28 June-2 July 2010.

[7] Migliaccio, F., Reguzzoni, M., Sanso, F., Tscherning, C.C. and Veicherts, M. (2010) GOCE Data Analysis: The Space-Wise Approach and the First Space-Wise Gravity Field Model. The ESA Living Planet Symposium, Bergen, 28 June-2 July 2010.

[8] Pail, R., Goiginger, H., Schuh, W.-D., Höck, E., Brockmann, J.M., Fecher, T., Gruber, T., Mayer-Gürr, T., Kusche, J., Jäggi, A. and Rieser, D. (2010) Combined Satellite Gravity Field Model GOCO01S Derived from GOCE and GRACE. Geophysical Research Letters, 37, Article ID: L20314.

[9] Förste, C., Bruinsma, S.L., Shako, R., Marty, J.C., Flechtner, F., Abrikosov, O., Dahle, C., Lemoine, J.M., Neumayer, K.H., Biancale, R., Barthelmes, F., König, R. and Balmino, G. (2011) EIGEN-6-A New Combined Global Gravity Field Model Including GOCE Data from the Collaboration of GFZ Potsdam and GRGS-Toulouse. Geophysical Research Abstracts, Vol. 13, EGU2011-3242-2, EGU General Assembly, Vienna.

[10] Förste, C., Bruinsma, S.L., Flechtner, F., Marty, J.C., Lemoine, J.M., Dahle, C., Abrikosov, O., Neumayer, K.H., Biancale, R., Barthelmes, F. and Balmino, G. (2012) A Preliminary Update of the Direct Approach GOCE Processing and a New Release of EIGEN-6C. $A G U$ Fall Meeting 2012, San Francisco, USA, 3-7 December 2012, Abstract No. G31B-0923.

[11] Förste, C., Bruinsma, S., Abrykosov, O., Flechtner, F., Marty, J.-C., Lemoine, J.-M., Dahle, C., Neumayer, K.-H., Barthelmes, F., König, R. and Biancale, R. (2014) EIGEN-6C4-The Latest Combined Global Gravity Field Model Including GOCE Data up to Degree and Order 1949 of GFZ Potsdam and GRGS Toulouse. Geophysical Research Abstracts, Vol. 16, EGU2014-3707, General Assembly European Geosciences Union, Vienna.

[12] Farahani, H., Ditmar, P., Klees, R., Liu, X., Zhao, Q. and Guo, J. (2013) The Static Gravity Field Model DGM-1S from GRACE and GOCE Data: Computation, Validation and an Analysis of GOCE Mission's Added Value. Journal of Geodesy, 87, 843-867. https:/doi.org/10.1007/s00190-013-0650-3

[13] Schall, J., Eicker, A. and Kusche, J. (2014) The ITG-Goce02 Gravity Field Model from GOCE Orbit and Gradiometer Data Based on the Short Arc Approach. Journal of Geodesy, 
88, 403-409. https:/doi.org/10.1007/s00190-014-0691-2

[14] Gruber, T., Visser, P.N.A.M., Ackermann, C. and Hosse, M. (2011) Validation of GOCEgravity Field Models by Means of Orbit Residuals and Geoid Comparisons. Journal of Geodesy, 85, 845-860. https:/doi.org/10.1007/s00190-011-0486-7

[15] Yi, W. and Rummel, R. (2014) A Comparison of GOCE Gravitational Models with EGM2008. Journal of Geodynamics, 73, 14-22. https:/doi.org/10.1016/j.jog.2013.10.004

[16] Hirt, C., Gruber, T. and Featherstone, W.E. (2011) Evaluation of the First GOCE Static Gravity Field Models Using Terrestrial Gravity, Vertical Deflections and EGM2008 Quasigeoid Heights. Journal of Geodesy, 85, 723-740. https:/doi.org/10.1007/s00190-011-0482-y

[17] Voigt, C., Rülke, A., Denker, H., Ihde, J. and Liebsch, G. (2010) Validation of GOCE Products by Terrestrial Data Sets in Germany. In: Observation of the System Earth from Space, Geotechnologien Science Report No. 17, 106-111.

[18] Voigt, C. and Denker, H. (2014) Regional Validation and Combination of GOCE Gravity Field Models and Terrestrial Data. In: Flechtner, F., Sneeuw, N. and Schuh, W.-D., Eds., Observation of the System Earth from Space, Geotechnologien Science Report No. 20, Springer, Berlin, 139-145. https:/doi.org/10.1007/978-3-642-32135-1_18

[19] Janák, J. and Pitonák, M. (2011) Comparison and Testing of GOCE Global Gravity Models in Central Europe. Journal of Geodetic Science, 1, 333-347.

https:/doi.org/10.2478/v10156-011-0010-2

[20] Godah, W. and Krynski, J. (2012) Validation of GOCE Geopotential Models over Poland Using the EGM2008 and GPS/Levelling Data. Geoinformation Issues, 3, 5-17.

[21] Sprlák, M., Gerlach, C. and Pettersen, B. (2012) Validation of GOCE Global Gravity Field Models Using Terrestrial Gravity Data in Norway. Journal of Geodetic Science, 2, 134-143. https:/doi.org/10.2478/v10156-011-0030-y

[22] Guimarães, G., Matos, A. and Blitzkow, D. (2012) An Evaluation of Recent GOCE Geopotential Models in Brazil. Journal of Geodetic Science, 2, 144-155. https:/doi.org/10.2478/v10156-011-0033-8

[23] Abdalla, A., Fashir, H.H., Ali, A. and Fairhead, D. (2012) Validation of Recent GOCE/ GRACE Geopotential Models Over Khartoum State-Sudan. Journal of Geodetic Sciences, 2, 88-97. https:/doi.org/10.2478/v10156-011-0035-6

[24] Godah, W. and Krynski, J. (2015) Comparison of GGMs Based on one Year GOCE Observations with the EGM2008 and Terrestrial Data over the Area of Sudan. International Journal of Applied Earth Observation \& Geoinformation, 35, 128-135. https:/doi.org/10.1016/j.jag.2013.11.003

[25] Elsaka, B., Alothman, A. and Godah, W. (2015) On the Contribution of GOCE SatelliteBased GGMs to Improve GNSS/Levelling Geoid Heights Determination in Saudi Arabia. IEEE Journal of Selected Topics in Applied Earth Observations and Remote Sensing, 9, 1-10. https:/doi.org/10.1109/JSTARS.2015.2495193

[26] Pavlis, N.K., Holmes, S.A., Kenyon, S.C. and Factor, J.K. (2012) The Development and Evaluation of the Earth Gravitational Model 2008 (EGM2008). Journal of Geophysical Research, 117, 1-38. https:/doi.org/10.1029/2011jb008916

[27] Tapley, B., Ries, J., Bettadpur, S., Chambers, D., Cheng, M., Condi, F., Gunter, B., Kang, Z., Nagel, P., Pastor, R., Pekker, T., Poole, S. and Wang, F. (2005) GGM02-An Improved Earth Gravity Field Model from GRACE. Journal of Geodesy, 79, 467-478. https:/doi.org/10.1007/s00190-005-0480-Z

[28] Lemoine, F.G., Kenyon, S.C., Factor, J.K., Trimmer, R.G., Pavlis, N.K., Chinn, D.S., Cox, C.M., Klosko, S.M., Luthcke, S.B., Torrence, M.H., Wang, Y.M., Williamson, R.G., Pavlis, 
E.C., Rapp, R.H. and Olson, T.R. (1998) The Development of the Joint NASA GSFC and the National Imagery and Mapping Agency (NIMA) Geopotential Model EGM96. NASA Tech. Publ. TP-1998-206861, Goddard Space Flight Center, Greenbelt.

[29] Merry, C. (2009) EGM2008 Evaluation for Africa. Newton's Bulletin Issue No. 4.

[30] Dawod, G. (2008) Towards the Redefinition of the Egyptian Geoid: Performance Analysis of Recent Global Geoid and Digital Terrain Models. Journal of Spatial Science, 53, 31-42. https:/doi.org/10.1080/14498596.2008.9635133

[31] Bruinsma, S., et al. (2013) The New ESA Satellite-Only Gravity Field Model via the Direct Approach. Geophysical Research Letters, 40, 3607-3612. https:/doi.org/10.1002/grl.50716

[32] Brockmann, J.M., Zehentner, N., Höck, E., Pail, R., Loth, I., Mayer-Gürr, T. and Schuh, W.-D. (2014) EGM-TIM-RL05: An Independent Geoid with Centimeter Accuracy Purely Based on the GOCE Mission. Geophysical Research Letters, 41, 8089-8099. https:/doi.org/10.1002/2014GL061904

[33] Gatti, A., Reguzzoni, M., Migliaccio, F. and Sansò, F. (2014) Space-Wise Grids of Gravity Gradients from GOCE Data at Nominal Satellite Altitude. 5th International GOCE User Workshop, Paris, 25-28 November 2014.

[34] Dawod, G. (1998) A National Gravity Standardization Network for Egypt. PhD Dissertation, Faculty of Engineering at Shoubra, Zagazig University, Zagazig.

[35] Kaula, W.M. (1966) Theory of Satellite Geodesy. Blaisdell Puplishing Company, Waltham, Republished 2000 by Dover Puplications Inc., Mineola.

[36] Heiskanen, W.A. and Moritz, H. (1967) Physical Geodesy. W.H. Freeman and Company, San Francisco.

[37] Torge, W. and Müller, J. (2012) Geodesy. 4th Edition, Walter de Gruyter, Berlin. https:/doi.org/10.1515/9783110250008

[38] Mayer-Gürr, T., Rieser, D., Höck, E., Brockmann, J.M., Schuh, W.-D., Krasbutter, I., Kusche, J., Maier, A., Krauss, S., Hausleitner, W., Baur, O., Jäggi, A., Meyer, U., Prange, L., Pail, R., Fecher, T. and Gruber, T. (2012) The New Combined Satellite Only Model GOCO03s. IAG Symposium Gravity, Geoid and Height Systems (GGHS), Venice, 8-12 October 2012.

[39] Rummel, R. (2010) GOCE: Gravitational Gradiometry in a Satellite. In: Freeden, W., Nashed, F.M.Z. and Sonar, T., Eds., Handbook of Geomathematics, Vol. 2, Springer, Berlin, 93-103. https:/doi.org/10.1007/978-3-642-01546-5_4

[40] Forsberg, R. (1984) A Study of Terrain Reductions, Density Anomalies and Geophysical Inversion Methods in Gravity Field Modelling. Report 355, Department of Geodetic Science and Surveying, Ohio State University, Columbus.

[41] Gruber, T. (2009) Evaluation of the EGM2008 Gravity Field by Means of GPS-Levelling and Sea Surface Topography Solutions. External Evaluation Reports of EGM2008, Newton's Bulletin, No. 4, 3-17.

[42] Kotsakis, C. and Sideris, M.G. (1999) On the Adjustment of Combined GPS/Levelling/ Geoid Networks. Journal of Geodesy, 73, 412-421. https:/doi.org/10.1007/s001900050261

[43] Fotopoulos, G. (2003) An Analysis on the Optimal Combination of Geoid, Orthometric and Ellipsoidal Height Data. UCGE Reports No. 20185, PhD Thesis, Department of Geomatics Engineering, University of Calgary, Calgary.

[44] Wessel, P., Smith, W.H.F., Scharroo, R., Luis, J.F. and Wobbe, F. (2013) Generic Mapping Tools: Improved Version Released. Eos, Transactions, American Geophysical Union, 94, 409-410. https:/doi.org/10.1002/2013EO450001 
Submit or recommend next manuscript to SCIRP and we will provide best service for you:

Accepting pre-submission inquiries through Email, Facebook, LinkedIn, Twitter, etc. A wide selection of journals (inclusive of 9 subjects, more than 200 journals)

Providing 24-hour high-quality service

User-friendly online submission system

Fair and swift peer-review system

Efficient typesetting and proofreading procedure

Display of the result of downloads and visits, as well as the number of cited articles

Maximum dissemination of your research work

Submit your manuscript at: http://papersubmission.scirp.org/

Or contact ijg@scirp.org 